\title{
ANALISIS TINGKAT KEPUASAN PETANI PADI SAWAH TERHADAP KINERJA PENYULUH PERTANIAN LAPANGAN DI KECAMATAN PANDAWAI KABUPATEN SUMBA TIMUR
}

\author{
ANALYSIS OF SATISFACTION LEVEL OF RICE FARMERS TOWARDS THE \\ PERFORMANCE OF FIELD AGRICULTURAL EXTENDERS IN PANDAWAI \\ DISTRICT, EAST SUMBA REGENCY
}

\author{
Insan Pebruwandi Saragih*, Elfis Umbu Katongu Retang \\ Program Studi Agribisnis Universitas Kristen Wira Wacana Sumba \\ Jl. R. Suprapto No. 35 Waingapu, Kabupaten Sumba Timur - NTT \\ *E-mail: insanpebruwandisaragih@yahoo.com \\ (Diterima 12-11-2021; Disetujui 22-01-2022)
}

\begin{abstract}
ABSTRAK
Penyuluhan dalam bidang pertanian merupakan sarana kebijakan yang dipergunakan oleh pemerintah dalam upaya mendorong pembangunan pertanian. Akan tetapi di lain pihak petani memiliki kebebasan, yaitu untuk menerima atau menolak program yang ditawarkan dalam kegiatan penyuluhan, sehingga dapat disimpulkan bahwa penyuluhan akan mencapai sasarannya jika perubahan yang diinginkan sesuai dengan apa yang diharapan petani. Kesesuaian tingkat harapan petani terhadap tingkat kinerja penyuluh merupakan faktor penting yang sangat mempengaruhi tingkat kepuasan petani tehadap kegiatan penyuluhan yang mereka dapatkan. Penelitian ini bertujuan untuk menganalisis kesesuaian antara tingkat harapan petani terhadap tingkat kinerja penyuluh berdasarkan atribut pelayanan penyuluh pertanian, dan tingkat kepuasan petani secara umum terhadap kinerja penyuluh pertanian. Penelitian ini dilakukan di Kecamatan Pandawai Kabupaten Sumba Timur, pada bulan Juli 2021 sampai bulan September 2021, dimana penelitian ini merupakan penelitian deskriptif kualitatif, dengan menggunakan metode analisis Importance Performance Analysis (IPA) dan Customer Satisfaction Index (CSI). Hasil perhitungan dengan metode IPA menunjukan tingkat kesesuaian harapan petani terhadap kinerja penyuluh berdasarkan atribut pelayanan penyuluh mencapai $77,02 \%$, dimana atribut dengan tingkat kesesuain tertinggi adalah atribut penyuluh mempersiapakan bahan bacaan, makanan dan minuman selama penyuluhan. Atribut dengan tingkat kesesuaian terendah adalah atribut penyuluh membantu petani/kelompok tani dalam menyusun rencana kegiatan usaha tani. Hasil analisis CSI tingkat kepuasan petani padi sawah terhadap kinerja penyuluh pertanian di Kecamatan Pandawai adalah sebesar 0,66. Nilai tersebut berada pada rentang 0,66-0,80. Hasil tersebut mengidentifikasi bahwa tingkat kepuasan petani padi sawah terhadap kinerja penyuluh di Kecamatan Pandawai berada dalam kategori puas.
\end{abstract}

Kata kunci: CSI, Harapan, IPA, Kepuasan, Kinerja

\begin{abstract}
Extension in agriculture is a policy tool used by the government in an effort to encourage agricultural development. However, on the other hand, farmers have the freedom, namely to accept or reject the program offered in extension activities, so it can be concluded that extension will achieve its goals if the desired changes are in accordance with what farmers expect. The suitability of the level of farmers' expectations with the level of performance of the extension workers is an important factor that greatly affects the level of satisfaction of farmers with the extension activities they get. This study aims to analyze the suitability between the level of expectations of farmers to the level of performance of the agricultural instructor based on the service attributes of the agricultural extension, and the level of satisfaction of farmers in general with the performance of
\end{abstract}


the agricultural instructor. This research was conducted in Pandawai District, East Sumba Regency, from July 2021 to September 2021, where this research is a qualitative descriptive study, using the Importance Performance Analysis (IPA) and Costomer Satisfaction Index (CSI) analysis methods. The results of calculations using the IPA method show that the level of conformity of farmers' expectations on the performance of the extension workers based on the service attributes of the extension workers reaches $77.02 \%$, where the attribute with the highest level of conformity is the attribute of the instructor preparing reading materials, food and drinks during the extension. The attribute with the lowest level of suitability is the attribute of the extension agent assisting farmers/farmer groups in planning farming activities. The results of the CSI analysis of the level of satisfaction of lowland rice farmers on the performance of agricultural extension workers in Pandawai District is 0.66. This value is in the range of 0.66-0.80. These results identify that the level of satisfaction of lowland rice farmers with the performance of extension workers in Pandawai District is in the satisfied category.

Keywords: CSI, Expectations, IPA, Satisfaction, Performance

\section{PENDAHULUAN}

Kegiatan penyuluhan menjadi salah satu faktor yang menentukan keberhasilan dalam sejarah pembangunan pertanian di Indonesia. Di masa orde baru, penyuluhan dalam bidang pertanian mendapat pengakuan dari masyarakat, yaitu dengan keberhasilan dalam swasembada beras nasional. Pada saat itulah lembaga penyuluhan pertanian menjadi objek yang harus memperjuangkan hak-hak petani. Dengan ketersediaan anggaran yang terbatas, lembaga penyuluhan memiliki tugas yang sangat besar yaitu meningkatkan swasembada beras (Bahua, 2015).

Undang-Undang Nomor 16 Tahun 2006 Tentang Sistem Penyuluhan Pertanian, Perikanan Dan Kehutanan (Indonesia), menyatakan bahwa penyuluhan adalah proses pembelajaran bagi pelaku utama serta pelaku usaha agar mereka mau dan mampu menolong dan mengorganisasikan dirinya dalam mengakses informasi pasar, teknologi, permodalan dan sumberdaya lainnya, sebagai upaya untuk meningkatkan produktivitas, efisiensi usaha, pendapatan dan kesejahteraannya serta meningkatkan kesadaran dalam pelestarian fungsi lingkungan hidup.

Petani pada umumnya tidak begitu memahami keadaan iklim, ekonomi dan juga sosial di wilayah mereka bekerja. Selain itu, pengaruh hama dan penyakit pada tanaman mengakibatkan petani tidak dapat meramal jumlah produksi pada usahataninya. Akan tetapi dengan segala keterbatasannya, petani sebagai pelaku utama dalam kegiatan pertaniannya harus mengambil keputusan, misalnya tentang banyaknya input produksi yang akan digunakan. Dalam hal ini, kegiatan penyuluhan 
diharapkan dapat berperan sebagai jembatan yang menghubungkan antara praktek yang dijalankan oleh petani dengan pengetahuan dan teknologi pertanian yang selalu berkembang.

Menurut Bahua (2016), pada era globalisasi kebijakan-kebijakan dalam penyuluhan mengalami perubahan, dimana kebijakan yang semula bertujuan untuk menjadikan petani terampil berproduksi, berubah menjadi kebijakan yang memotivasi petani untuk lebih rasional dalam mengembangkan usahatani berdasarkan kemampuan, sumber daya lokal dan potensi pasar yang ada. Hal ini tentu saja membutuhkan kinerja PPL yang lebih baik lagi dalam menerapkan program penyuluhan sesuai dengan kebutuhan para petani.

Kabupaten Sumba Timur sebagai salah satu kabupaten yang memiliki potensi padi sawah, berkomitmen untuk mewujudkan swasembada pangan di daerah tersebut dan berupaya menjadi salah satu lumbung beras di Provinsi Nusa Tenggara Timur. Upaya yang telah dilakukan Pemerintah Daerah Kabupaten Sumba Timur dalam meningkatkan kinerja pembangunan di bidang pertanian diantaranya, yaitu mendorong pemanfaatan teknologi tepat guna yang ramah lingkungan, meningkatkan kuantitas dan kualitas SDM pertanian, dan mendorong tumbuh kembangnya usaha pertanian yang dapat memberikan nilai tambah ekonomi bagi masyarakat.

Kecamatan Pandawai merupakan salah satu kecamatan di Kabupaten Sumba Timur dengan potensi pertanian padi sawah yang sangat baik. Pertanian padi sawah di Kecamatan Pandawai didukung potensi lahan yang sesuai dengan kebutuhan pembudidayaan padi sawah, dan potensi air yang berasal dari irigasi teknis bendungan Kambaniru, bendungan Harau, dan bendungan Kadumbul. Pada tahun 2015 produktivitas padi sawah di Kecamatan Pandawi mencapai 41,69 Kw/Ha, dimana angka tersebut melampaui rata-rata produktivitas padi sawah di Kabupaten Sumba Timur yaitu 41,34 pada tahun yang sama (BPS Sumba Timur, 2019).

Permasalahan yang dirasakan oleh petani terkait kegiatan penyuluhan saat ini khususnya di Kecamatan Pandawai adalah materi penyuluhan yang kurang sesuai dengan harapan petani. Masalah ini merupakan gambaran dari gagalnya PPL dalam memberikan kepuasan maksimal kepada petani, dimana PPL belum dapat memahami dan menangkap apa yang dibutuhkan petani. Kegiatan penyuluhan belum mampu secara 
maksimal menjalankan perannya dapat disebabkan karena partisipasi petani yang sangat rendah pada kegiatan penyuluh pertanian, hal ini menjadi akibat dari mutu pelayanan yang belum sesuai dengan harapan petani.

Penyuluhan pertanian merupakan sarana kebijakan yang digunakan pemerintah untuk mendorong pembangunan pertanian. Dilain pihak, petani mempunyai kebebasan untuk menerima atau menolak saran yang diberikan oleh PPL. Dengan demikian penyuluhan hanya dapat mencapai sasarannya jika perubahan yang diinginkan sesuai dengan kepentingan petani (Mahyuddin et al., 2018).

Adapun tujuan dari penelitian ini adalah untuk menganalisis tingkat kesesuaian antara tingkat harapan terhadap tingkat kinerja pada atributatribut kinerja penyuluh pertanian dan menganalisis tingkat kepuasan petani padi sawah terhadap kinerja PPL di Kecamatan Pandawai. Penelitian ini penting dilakukan sebagai bahan evaluasi untuk meningkatkan kinerja PPL dan meningkatkan kepuasan petani ke depannya.

\section{METODE PENELITIAN}

Penentuan daerah penelitian dilakukan secara purposive sampling, yaitu ditetapkan secara sengaja di wilayah kerja penyuluhan BP3K Kecamatan Pandawai Kabupaten Sumba Timur, dengan pertimbangan Kecamatan Pandawai merupakan salah satu kecamatan dengan potensi pertanian padi sawah berkelanjutan di Kabupaten Sumba Timur, dengan musim tanam mencapai 3 kali dalam setahun. Penelitian dilaksanakan pada bulan Juli 2021 sampai bulan September 2021.

Data yang digunakan pada penelitian ini adalah data kualitatif, dengan dua sumber data, yaitu sumber data primer dan sumber data sekunder Data primer diperoleh dari sampel melalui wawancara dengan menggunakan kuisioner yang telah dipersiapkan. Data sekunder diperoleh dari instansi terkait seperti Badan Pusat Statistik Kabupaten Sumba Timur dan Provinsi Nusa Tenggara Timur.

Teknik pengambilan sampel dilakukan dengan menggunakan metode Proportional Sampling yaitu menentukan anggota sampel dengan mengambil wakil tiap-tiap kelompok yang ada dalam populasi yang jumlahnya disesuaikan dengan jumlah anggota subjek yang 
berada pada masing-masing kelompok tersebut (Arikunto, 2006). Perhitungan menggunakan rumus Dixon dan B. Leach, yaitu:

$\mathrm{n}^{\prime}=\frac{\mathrm{PDn}}{\sum \mathrm{P}} \mathrm{xJS}$

Keterangan :

n' = Jumlah sampel per kelurahan

PDn $=$ Petani padi pada kelurahan $n$

$\Sigma \mathrm{P}=$ Petani padi di Kecamatan Pandawai

JS = Jumlah sampel yang akan diambil

Hasil perhitungan jumlah sampel petani padi per desa/kelurahan di Kecamatan pandawai dapat dilihat pada Tabel 1.

Tabel 1. Tabel Jumlah Sampel per Desa/Kelurahan

\begin{tabular}{ccc}
\hline $\begin{array}{c}\text { Desa/ } \\
\text { Kelurahan }\end{array}$ & $\begin{array}{c}\text { Jumlah } \\
\text { Petani Padi }\end{array}$ & $\begin{array}{c}\text { Jumlah } \\
\text { Sampel }\end{array}$ \\
\hline Mau Bokul & 82 & 8 \\
Kadumbul & 217 & 22 \\
Palakahembi & 305 & 30 \\
Kawangu & 693 & 70 \\
\hline Total & $\mathbf{1 . 2 9 7}$ & $\mathbf{1 3 0}$ \\
\hline
\end{tabular}

Sumber : Data primer setelah diolah tahun 2021

Penentuan sampel dilakukan dengan metode acak sederhana (Simple Random Sampling) namun dengan ketentuan petani padi sawah yang yang menjadi anggota kelompok tani, dan merupakan rekomendasi dari pengurus kelompok tani, berdasarkan keaktifan di dalam kelompok dalam mengikuti kegiatan-kegiatan penyuluhan.
Data kemudian dianalisis secara deskriptif menggunakan metode Importance Perfomance Analysis (IPA). Menurut Wijaya (2018), metode IPA yang berupa diagram kartesius adalah prosedur untuk menunjukkan kepentingan relatif berbagai indikator dalam menentukan indikator-indikator yang mendasar, sehingga dapat mengindikasikan area atau indikator dalam peningkatan kualitas jasa. IPA menganalisis tingkat kesesuaian, yaitu perbandingan antara skor pelayanan yang diberikan dengan skor harapan pelanggan. Tingkat kesesuaian tersebut menentukan urutan prioritas faktor-faktor kepuasan pelanggan yang perlu ditingkatkan. Tingkat kesesuian dihitung dengan rumus berikut:

$T K=\frac{X i}{Y i} \quad \times 100 \%$

Keterangan :

$\mathrm{TK}=$ Tingkat kesesuaian atribut

$\mathrm{Xi}=$ Skor penilaian tingkat kinerja

Yi $=$ Skor penilaian tingkat harapan.

Setelah mendapatkan tingkat kesesuaian atribut pelayanan PPL, selanjutnya nilai rata-rata dari masingmasing atribut pelayanan PPL dipetakan pada diagram kartesius, dimana sumbu mendatar (X) sebagai skor dari pencapaian tingkat kinerja, sedangkan sumbu tegak (Y) sebagai skor tingkat 
harapan. Nilai rata-rata sumbu $\mathrm{X}$ dan $\mathrm{Y}$ yang digunakan dalam pemetaan pada diagram kartesius diperoleh melalui rumus:

$\overline{\mathrm{X}}=\frac{\sum \mathrm{Xi}}{n}$

$\overline{\mathrm{Y}}=\frac{\sum \mathrm{Yi}}{n}$

Keterangan :

$\overline{\mathrm{X}} \mathbf{i}=$ Rata-rata total tingkat kinerja

$\bar{Y} \mathbf{i}=$ Rata-rata total tingkat harapan

$\mathrm{n}=$ Jumlah responden

Diagram kartesius dibagi oleh dua garis yang berpotongan tegak lurus pada titik $(X, Y)$. Titik $X$ sebagai titik skor ratarata tingkat kinerja seluruh atribut sedangkan titik Y sebagai titik skor ratarata tingkat kepentingan seluruh atribut. Titik (X,Y) diperoleh melalui rumus berikut :

$\mathrm{X}=\frac{\sum \mathrm{X}}{K}$

$\mathrm{Y}=\frac{\sum \mathrm{Y}}{K}$

Keterangan :

$\mathrm{K}=$ Total jumlah atribut pelayanan

Setiap kuadran yang berada pada diagram kartesius menjelaskan keadaan yang berbeda, yaitu:

1. Kuadran A mengidentifikasi indikator yang dianggap sangat mempengaruhi kepuasan pelanggan. Misalnya unsurunsur jasa yang dianggap sangat penting, namun manajemen belum melaksanakannya sesuai dengan harapan pelanggan.

2. Kuadran B, menjelaskan keberhasilan yang telah dilaksanakan perusahaan, dan wajib untuk dipertahankannya. Dianggap sangat penting dan sangat memuaskan.

3. Kuadran C, menunjukkan beberapa faktor yang kurang penting pengaruhnya menurut pelanggan, dan pelaksanaannya oleh perusahaan juga belum maksimal.

4. Kuadran D, menunjukkan indikator yang menurut pelanggan kurang penting, akan tetapi pelaksanaanya sangat memuaskan. Hal ini dinilai sebagai pemborosan (Supranto, 2011).

Untuk mengetahui tingkat kepuasan petani padi sawah terhadap kinerja penyuluh pertanian di Kecamatan Pandawai, digunakan metode Customer Satisfaction Index (CSI). Menurut Syukri (2014) CSI merupakan indeks untuk menentukan tingkat kepuasan pelanggan secara menyeluruh dengan pendekatan yang mempertimbangkan tingkat kepentingan dari atribut-atribut yang diukur. Metode pengukuran indeks kepuasan pelanggan CSI meliputi tahaptahap sebagai berikut: 
1. Menghitung weighting factors.

Merubah nilai rataan tingkat harapan ke dalam bentuk persentase dari total nilai rataan tingkat harapan untuk seluruh atribut yang diuji, sehingga nantinya didapatkan jumlah nilai weighting factors sebesar $100 \%$.

2. Menghitung weighted score. Nilai ini merupakan perkalian diantara nilai rataan tingkat kinerja dari masingmasing atribut dengan weighting factors masing-masing atribut.

3. Menentukan nilai weighted total. Nilai weighted total merupakan hasil penjumlahan nilai weighted score dari semua atribut kualitas jasa.

4. Nilai satisfaction index (indeks kepuasan). Yaitu hasil perhitungan dari nilai weighted total dibagi skala maksimal yang digunakan pada penelitian (dalam penelitian ini skala maksimal adalah lima), lalu hasilnya dikali dengan 100\%. Tingkat kepuasan pelanggan secara menyeluruh dapat dilihat dari kriteria tingkat kepuasan pelanggan atau konsumen, dengan kriteria berikut ini:

- $0,00-0,34=$ Tidak Puas

- $0,35-0,50=$ Kurang Puas

- $0,51-0,65=$ Cukup Puas

- $0,66-0,80=$ Puas

- $\quad 0,81-1,00=$ Sangat Puas
HASIL DAN PEMBAHASAN

Gambaran Umum Wilayah

Kecamatan Pandawai

Kecamatan Pandawai merupakan salah satu dari 22 (dua puluh dua) kecamatan yang berada di Kabupaten Sumba Timur, dengan ketinggian wilayahnya berada pada $0-1.225$ meter dari permukaan laut, kemiringan berkisar antara $0-8 \%$, dan memiliki iklim tropis dengan curah hujan yang sangat rendah dan tidak merata tiap tahun. Musim penghujan relatif pendek yaitu rata-rata 4-5 bulan, dan musim kemarau rata-rata selama 8 bulan). Suhu di Kecamatan Pandawai berkisar 22,5 - 31,7 derajat Celcius, sehingga wilayah Kecamatan Pandawai ini termasuk daerah beriklim kering. Luas wilayah Kecamatan Pandawai adalah 412,6 $\mathrm{km}^{2}$, dengan perbatasan wilayah berikut ini:

- Utara = Selat Sumba

- Selatan = Kecamatan Kahaungu Eti dan Kambata Mapambuhang

- Timur $=$ Kecamatan Umalulu

- Barat = Kecamatan Kambera (BPS Sumba Timur, 2020)

Luas panen, rata-rata produksi dan produksi beberapa komoditas pertanian di Kecamatan Pandawai pada tahun 2015 diuraikan pada Tabel 2. 
Tabel 2. Luas Panen, Produksi dan Rata-Rata Produksi Komoditas Pertanian di Kecamatan Pandawai Tahun 2015

\begin{tabular}{ccccc}
\hline No. & Komoditas & $\begin{array}{c}\text { Luas lahan } \\
\text { (ha) }\end{array}$ & $\begin{array}{c}\text { Produksi } \\
\text { (ton) }\end{array}$ & $\begin{array}{c}\text { Rata-rata produksi } \\
\text { (kw/ha) }\end{array}$ \\
\hline 1. & Padi sawah & 1.046 & 4.361 & 41,60 \\
2. & Padi ladang & 45 & 2.338 & 39,67 \\
3. & Jagung & 944 & 3.384 & 5,47 \\
4. & Ubi kayu & 86 & 885 & 102,91 \\
5. & Ubi jalar & 52 & 380 & 73,08 \\
6. & Kacang tanah & 89 & 102 & 11,46 \\
7. & Kacang hijau & 63 & 18 & 2,86 \\
\hline
\end{tabular}

Sumber: BPS Sumba Timur, 2020

\section{Karakteristik Responden}

Deskripsi karakteristik petani padi sawah di Kecamatan Pandawai yang menjadi responden pada penelitian ini digambarkan pada beberapa kriteria, antara lain: umur, tingkat pendidikan, dan luas lahan. Karakteristik responden selengkapnya dapat dilihat pada Tabel 3.

Tabel 3. Karakteristik Responden

\begin{tabular}{|c|c|c|c|}
\hline Konlytarictil & Kotonori & & \\
\hline Karakterıstik & Kategor1 & Orang & $(\%)$ \\
\hline & $15-31$ & 16 & 12,31 \\
\hline & $32-48$ & 103 & 79,23 \\
\hline Umur (Tahun) & $49-65$ & 11 & 8,46 \\
\hline & $>65$ & 0 & 0,00 \\
\hline Total & & 130 & 100,00 \\
\hline Rata-rata umur (tahun) & & & \\
\hline & TS (Tidak Sekolah) & 34 & 26,15 \\
\hline & SD & 43 & 33,08 \\
\hline Tingkat pendidikan & SLTP & 16 & 12,31 \\
\hline & SLTA & 36 & 27,69 \\
\hline & Sarjana & 1 & 0,77 \\
\hline Total & & 130 & 100,00 \\
\hline Rata-rata tingkat pendidikan & & & \\
\hline & $<5.000$ & 6 & 4,61 \\
\hline Luas lahan $\left(\mathrm{M}^{2}\right)$ & $5.000-20.000$ & 122 & 93,85 \\
\hline & $>20.000$ & 2 & 1,54 \\
\hline Total & & 130 & 100,00 \\
\hline Rata-rata $\left(\mathrm{M}^{2}\right)$ & & & \\
\hline
\end{tabular}

Sumber: Data primer diolah (2021)

Pada Undang-Undang No.13 Tahun 2003 Tentang Ketenagakerjaan (Indonesia), disebutkan bahwa tenaga kerja yang produktif tingkat umurnya 1564 tahun. Data umur responden pada Tabel 3 memperlihatkan bahwa seluruh responden di kecamatan Pandawai berada pada umur produktif. Umur petani berpengaruh pada produksi usahataninya, dimana petani yang berada pada umur produktif memiliki fisik yang kuat, memiliki semangat kerja yang tinggi, dan memiliki semangat ingin tahu tentang apa yang mereka belum ketahui, sehingga 
dengan demikian mereka berusaha untuk melakukan adopsi suatu inovasi.

Tingkat pendidikan responden di Kecamatan Pandawai sebagian besar pada kategori rendah, yaitu sebanyak $33,08 \%$ responden berpendidikan setingkat $\mathrm{SD}$, dan responden yang tidak bersekolah yaitu sebanyak 26,15\%. Faktor pendidikan sangat berpengaruh dalam hal penerimaan inovasi (Makatita \& Isbandi, 2014).

Berdasarkan luas lahan, petani dapat dikelompokkan menjadi empat kategori, yaitu: petani luas dengan lahan $>2$ ha, petani sedang dengan lahan $0,5-$ 2 ha, petani sempit dengan luas lahan $<$

0,5 ha, dan buruh tani yaitu petani yang tidak memiliki lahan (Hernanto, 1989). Berdasarkan luas lahan yang dimiliki, sebagian besar responden di Kecamatan Pandawai masuk pada kategori petani sedang, yaitu sebanyak $93,85 \%$ dari keseluruhan jumlah responden.

\section{Atribut-Atribut Pelayanan PPL}

Atribut-atribut yang digunakan dalam menilai tingkat kepuasan petani terhadap tingkat kinerja dari PPL di Kecamatan Pandawai merupakan atribut pelayanan penyuluhan pertanian. Atributatribut tersebut dapat dilihat pada Tabel 4.

Tabel 4. Atribut-atribut Penilaian Tingkat Harapan Dan Kinerja Pada Penyuluh Pertanian Lapangan Dimensi Atribut-atribut

\begin{tabular}{|c|c|c|c|}
\hline 1 & $\begin{array}{l}\text { Tangible } \\
\text { (Berwujud) }\end{array}$ & $\begin{array}{l}\text { P1 } \\
\text { P2 } \\
\text { P3 }\end{array}$ & $\begin{array}{l}\text { Kerapian dan penampilan Penyuluh } \\
\text { Kerapian dan kebersihan ruangan } \\
\text { Kelengkapan alat peraga }\end{array}$ \\
\hline \multirow[t]{9}{*}{2} & Reliability & P4 & Praktek langsung di lapangan pada saat pelatihan dan kunjungan \\
\hline & (Keandalan) & P5 & Melaksanakan pelatihan dan kunjungan secara teratur \\
\hline & & P6 & Pengupayaan sarana dan prasarana yang dibutuhkan petani \\
\hline & & P7 & $\begin{array}{l}\text { Penyuluh membantu petani/kelompok tani dalam menyusun rencana kegiatan } \\
\text { usaha tani }\end{array}$ \\
\hline & & P8 & $\begin{array}{l}\text { Membantu petani/kelompok tani membuat administrasi kelompok seperti } \\
\text { proposal RDKK, buku administrasi, laporan bulanan, dll.. }\end{array}$ \\
\hline & & P9 & Penyuluh menyampaikan informasi teknologi terbaru \\
\hline & & $\mathrm{P} 10$ & Penyuluh menyampaikan informasi pasar \\
\hline & & P11 & Penyuluh menyampaikan informasi permodalan \\
\hline & & $\mathrm{P} 12$ & Pengaruh penyuluh terhadap peningkatan hasil usaha tani \\
\hline \multirow[t]{3}{*}{3} & $\begin{array}{l}\text { Responsivenes } \\
s \text { (Kesigapan) }\end{array}$ & P13 & $\begin{array}{l}\text { Kemampuan penyuluh untuk cepat tanggap dalam menghadapi masalah yang } \\
\text { timbul }\end{array}$ \\
\hline & & P14 & Kecepatan dalam menangani pengaduan petani \\
\hline & & $\mathrm{P} 15$ & Kecepatan dalam menyampaikan informasi terbaru \\
\hline \multirow[t]{4}{*}{4} & $\begin{array}{l}\text { Assurance } \\
\text { (Kepastian) }\end{array}$ & P16 & $\begin{array}{l}\text { Memberikan bimbingan dan memecahkan masalah petani/kelompok tani } \\
\text { dalam pengambilan keputusan guna menjalin kemitraan usaha dibidang } \\
\text { pertanian }\end{array}$ \\
\hline & & P17 & $\begin{array}{l}\text { Pengetahuan dan kecakapan dalam memberikan informasi yang jelas dan } \\
\text { mudah dimengerti kepada petani. }\end{array}$ \\
\hline & & $\mathrm{P} 18$ & Melayanani/menyelesaikan masalah secara tuntas \\
\hline & & P19 & $\begin{array}{l}\text { Pengetahuan dan kemampuan penyuluh dalam mengetahui permasalahan di } \\
\text { lapangan (Hama, Penyakit, dll) }\end{array}$ \\
\hline
\end{tabular}




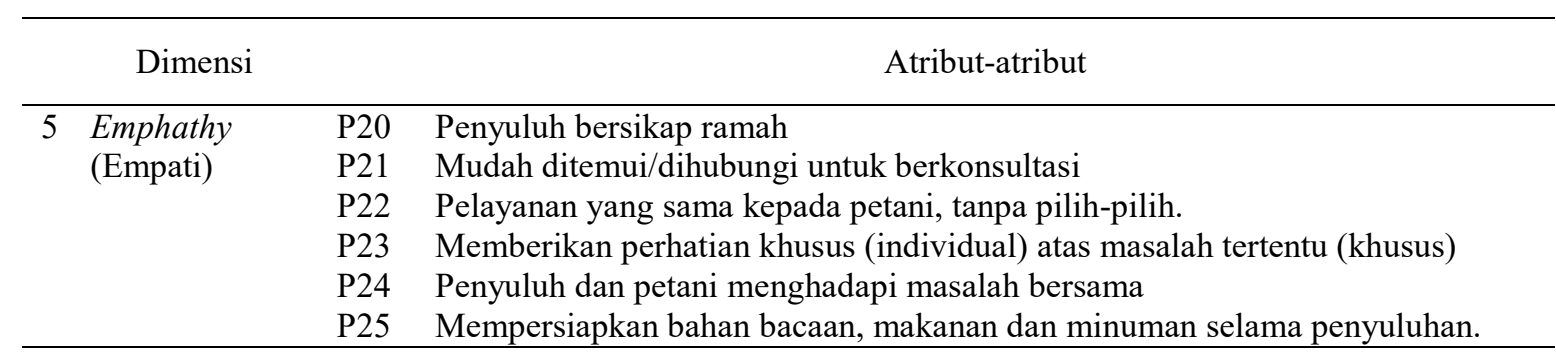

Tingkat Kesesuain Atribut Pelayanan

\section{PPL di Kecamatan Pandawai}

Tingkat kesesuaian atribut

pelayanan PPL merupakan persentase

perbandingan antara total tingkat harapan dengan total tingkat kinerja pada atribut pelayanan PPL. Analisis tingkat kesesuain atribut pelayanan PPL di Kecamatan Pandawai dapat dilihat pada Tabel 5.

Tabel 5. Tingkat Kesesuaian Atribut Pelayanan Penyuluh di Kecamatan Pandawai

\begin{tabular}{|c|c|c|c|c|c|c|c|c|}
\hline \multirow[b]{2}{*}{ No } & \multirow[b]{2}{*}{ Atribut } & \multicolumn{3}{|c|}{ Tingkat Harapan } & \multicolumn{3}{|c|}{ Tingkat Kinerja } & \multirow{2}{*}{$\begin{array}{c}\text { Tingkat } \\
\text { Kesesuaian } \\
\mathbf{( \% )} \\
\end{array}$} \\
\hline & & Bobot & $\begin{array}{c}\text { Rata- } \\
\text { rata }\end{array}$ & Keterangan & Bobot & $\begin{array}{c}\text { Rata- } \\
\text { rata }\end{array}$ & Keterangan & \\
\hline 1 & P1 & 563 & 4,33 & Sangat Penting & 357 & 2,75 & Cukup Puas & 63,41 \\
\hline 2 & $\mathrm{P} 2$ & 560 & 4,31 & Sangat Penting & 410 & 3,15 & Cukup Puas & 73,21 \\
\hline 3 & P3 & 594 & 4,57 & Sangat Penting & 305 & 2,35 & Kurang Puas & 51,35 \\
\hline 4 & P4 & 588 & 4,52 & Sangat Penting & 420 & 3,23 & Cukup Puas & 71,43 \\
\hline 5 & P5 & 580 & 4,46 & Sangat Penting & 316 & 2,43 & Kurang Puas & 54,48 \\
\hline 6 & P6 & 601 & 4,62 & Sangat Penting & 329 & 2,53 & Kurang Puas & 54,74 \\
\hline 7 & P7 & 592 & 4,55 & Sangat Penting & 300 & 2,31 & Kurang Puas & 50,68 \\
\hline 8 & P8 & 525 & 4,04 & Penting & 372 & 2,86 & Cukup Puas & 70,86 \\
\hline 9 & P9 & 641 & 4,93 & Sangat Penting & 420 & 3,23 & Cukup Puas & 65,52 \\
\hline 10 & P10 & 547 & 4,21 & Sangat Penting & 320 & 2,46 & Kurang Puas & 58,50 \\
\hline 11 & $\mathrm{P} 11$ & 368 & 2,83 & Cukup Penting & 393 & 3,02 & Cukup Puas & 106,79 \\
\hline 12 & $\mathrm{P} 12$ & 605 & 4,65 & Sangat Penting & 347 & 2,67 & Cukup Puas & 57,36 \\
\hline 13 & $\mathrm{P} 13$ & 596 & 4,58 & Sangat Penting & 400 & 3,08 & Cukup Puas & 67,11 \\
\hline 14 & P14 & 604 & 4,65 & Sangat Penting & 492 & 3,78 & Puas & 81,46 \\
\hline 15 & P15 & 599 & 4,61 & Sangat Penting & 504 & 3,88 & Puas & 84,14 \\
\hline 16 & P16 & 542 & 4,17 & Penting & 555 & 4,27 & Sangat Puas & 102,40 \\
\hline 17 & P17 & 609 & 4,68 & Sangat Penting & 555 & 4,27 & Sangat Puas & 91,13 \\
\hline 18 & P18 & 604 & 4,65 & Sangat Penting & 427 & 3,28 & Cukup Puas & 70,70 \\
\hline 19 & P19 & 579 & 4,45 & Sangat Penting & 470 & 3,62 & Puas & 81,17 \\
\hline 20 & $\mathrm{P} 20$ & 567 & 4,36 & Sangat Penting & 575 & 4,42 & Sangat Puas & 101,41 \\
\hline 21 & $\mathrm{P} 21$ & 567 & 4,36 & Sangat Penting & 581 & 4,47 & Sangat Puas & 102,47 \\
\hline 22 & $\mathrm{P} 22$ & 572 & 4,40 & Sangat Penting & 584 & 4,49 & Sangat Puas & 102,10 \\
\hline 23 & $\mathrm{P} 23$ & 599 & 4,61 & Sangat Penting & 400 & 3,08 & Cukup Puas & 66,78 \\
\hline 24 & P24 & 549 & 4,22 & Sangat Penting & 429 & 3,30 & Cukup Puas & 78,14 \\
\hline 25 & $\mathrm{P} 25$ & 373 & 2,87 & Cukup Penting & 441 & 3,39 & Cukup Puas & 118,23 \\
\hline
\end{tabular}




\begin{tabular}{|c|c|c|c|c|c|c|c|c|}
\hline \multirow[b]{2}{*}{ No } & \multirow[b]{2}{*}{ Atribut } & \multicolumn{3}{|c|}{ Tingkat Harapan } & \multicolumn{3}{|c|}{ Tingkat Kinerja } & \multirow{2}{*}{$\begin{array}{c}\text { Tingkat } \\
\text { Kesesuaian } \\
(\%)\end{array}$} \\
\hline & & Bobot & $\begin{array}{c}\text { Rata- } \\
\text { rata }\end{array}$ & Keterangan & Bobot & $\begin{array}{c}\text { Rata- } \\
\text { rata }\end{array}$ & Keterangan & \\
\hline & Rata-rata & & 4,35 & & & 3,29 & & 77,02 \\
\hline
\end{tabular}

Sumber: Data primer diolah (2021)

Pada Tabel 5 terlihat kesesuain antara tingkat harapan dan tingkat kinerja PPL menurut petani padi sawah di Kecamatan Pandawai mencapai 77,02\%, dimana atribut yang memiliki tingkat kesesuaian yang paling tinggi adalah atribut mempersiapkan bahan bacaan, makanan dan minuman selama penyuluhan (P25), yaitu sebesar $118,23 \%$. Keadaan ini menggambarkan ketersediaan bahan bacaan, makanan, dan minuman selama penyuluhan tergolong tinggi, dan petani merasa puas karena selama penyuluhan merasakan nuansa yang berbeda,suasana yang baru serta mendapatkan fasilitas yang layak selama penyuluhan berlangsung.

Petani merasa sangat puas, dan bahkan melebihi dari apa yang mereka harapkan ketika penyuluh mempersiapakan bahan bacaan, makanan dan minuman selama kegiatan penyuluhan. Disamping itu, petani menyukai metode praktek langsung di lapangan ataupun praktek dengan menggunkan alat peraga, sehingga mereka merasa ketersediaan bahan bacaan tidak terlalu penting..
Atribut penyuluh membantu petani/kelompok tani dalam menyusun rencana kegiatan usaha tani (P7) menjadi atribut dengan tingkat kesesuaian yang paling rendah, yaitu sebesar 50,68\%. Pada pelaksanaan di lapangan, petani merasa keaktifan penyuluh dalam membantu petani/kelompok tani menyusun rencana kegiatan usaha tani masih kurang. Hal ini menunjukkan bahwa kinerja penyuluh dalam membantu petani/kelompok tani dalam menyusun rencana kegiatan usaha tani masih jauh dari harapan petani. Petani sangat mengharapkan campur tangan penyuluh dalam membantu mereka menyusun rencana kegiatan usaha yang lebih terstruktur dan terukur dimana disesuaikan dengan keadaan pasar. Hal ini bertolak belakang dengan penelitian Ariana et al (2021), dimana menurut petani keterlibatan penyuluh sangat nyata dalam memotivasi dan memberi solusi untuk meningkatkan hasil produksi padi, dimana peran penyuluh yaitu membimbing dalam perencanaan usahatani berpengaruh secara signifikan terhadap produksi padi sawah di Desa 
Cibuniasih, Kecamatan Pancatengah, Kabupaten Tasikmalaya.

\section{Posisi Tingkat Harapan dan Tingkat Kinerja pada Kuadran IPA}

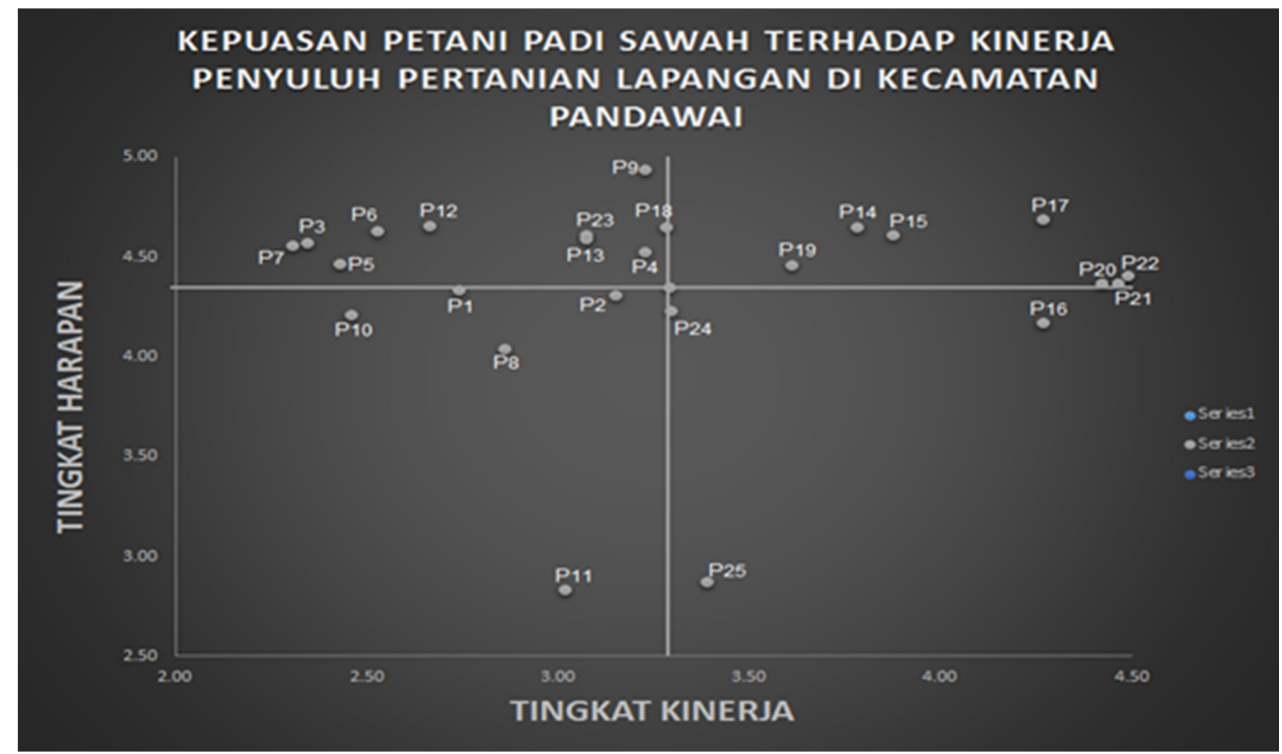

Gambar 1. Letak Titik Atribut-atribut Penilian Pada Diagram Kartesius

Berdasarkan hasil analisis metode IPA dengan menggunakan diagram kartesius pada atribut pelayanan penyuluh yang mempengaruhi kepuasan petani padi sawah di Kecamatan Pandawai terbagi menjadi empat kuadran, yaitu kuadran A sebagai atribut prioritas utama, kuadran B sebagai atribut pertahankan prestasi, kuadran C sebagai atribut prioritas rendah, dan kuadran D sebagai atribut berlebih. Pada kuadran A terdapat sepuluh atribut pelayanan penyuluh pertanian, yaitu: P3 (Kelengkapan alat peraga), P4 (Praktek langsung di lapangan pada saat pelatihan
Hasil analisis metode IPA terhadap atribut pelayanan PPL di Kecamatan Pandawai dapat dilihat pada Gambar 1. 
bahwa semua atribut yang berada pada kuadran A ini merupakan atribut yang yang menjadi prioritas utama untuk diperbaiki dan ditingkatkan oleh penyuluh.

Pada kuadran B terdapat tujuh atribut pelayanan penyuluh pertanian yang harus dipertahankan kinerjanya, yaitu: P14 (Kecepatan dalam menangani pengaduan petani), P15 (Kecepatan dalam menyampaiakan informasi terbaru), P17 (Kecakapan dalam memberikan informasi yang jelas dan mudah dimengerti), P19 (Pengetahuan dan kemampuan penyuluh dalam mengetahui permasalah di lapangan), P20 (Penyuluh bersikap ramah), P21 (Mudah ditemui/ditemui untuk berkonsultasi), P22 (Pelayanan yang sama terhadap petani tanpa pilih-pilih). Atribut pelayanan yang berada pada kuadran B menggambarkan bahwa atribut tersebut telah dilaksanakan sesuai dengan harapan petani, sehingga ketujuh atribut pelayanan yang termasuk pada kuadran ini harus dipertahankan dalam pelaksanaan di lapangan, dan dapat menjadi tolak ukur dari kepuasan petani padi sawah terhadap pelayanan penyuluh pertanian di Kecamatan Pandawai.

Pada kuadran C terdapat lima atribut pelayanan penyuluh pertanian, yaitu: P1 (Kerapian dan penampilan penyuluh), P2 (Kerapian dan kebersihan ruangan), P8 (Membantu petani/kelompok tani membuat administrasi kelompok), P10 (Penyuluh menyampaikan informasi pasar), P11 (Penyuluh menyampaikan informasi permodalan). Atribut pelayanan penyuluh yang terletak pada kuadran $\mathrm{C}$ memiliki tingkat harapan dan tingkat kinerja yang rendah, dimana atribut-atribut tersebut tidak terlalu diprioritaskan karena dianggap kurang penting oleh petani padi sawah di Kecamatan Pandawai.

Pada kuadran D terdapat tiga atribut pelayanan penyuluh pertanian, yaitu: P16 (Memberikan bimbingan dan memecahkan masalah dalam menjalin kemitraan), P24 (Penyuluh dan petani menghadapi masalah bersama), P25 (Mempersiapkan bahan bacaan, makanan dan minuman selama penyuluhan). Ketiga atribut yang termasuk pada kuadran $\mathrm{C}$ ini dianggap sebagai atribut berlebih, karena atribut-atribut tersebut memiliki tingkat harapan yang rendah dibandingkan atribut lainnya, tetapi tingkat pelaksanaan kinerja tinggi. 
Nilai CSI Tingkat Kepuasan Petani

Padi Sawah Terhadap Kinerja PPL di

\section{Kecamatan Pandawai}

Pada penelitian ini analisis

Customer Satisfaction Index (CSI)

digunakan untuk mengukur kepuasan

petani padi sawah terhadap kinerja PPL di Kecamatan Pandawai secara keseluruhan dengan mempertimbangkan tingkat kepentingan dan tingkat kinerja dari 25 atribut kinerja penyuluh pertanian. Adapun hasil analisis CSI dapat dilihat pada Tabel 6.

Tabel 6. Nilai CSI Kualitas Pelayanan PPL Terhadap Petani Padi Sawah Di Kecamatan Pandawai

\begin{tabular}{cccccc}
\hline No & Atribut & $\begin{array}{c}\text { Rata-rata Tingkat } \\
\text { Harapan }\end{array}$ & $\begin{array}{c}\text { Weight } \\
\text { Factor }\end{array}$ & $\begin{array}{c}\text { Rata-rata Tingkat } \\
\text { Kinerja }\end{array}$ & $\begin{array}{c}\text { Weight } \\
\text { Factor }\end{array}$ \\
\hline 1 & P1 & 4,33 & 0,04 & 2,75 & 0,11 \\
2 & P2 & 4,31 & 0,04 & 3,15 & 0,13 \\
3 & P3 & 4,57 & 0,04 & 2,35 & 0,10 \\
4 & P4 & 4,52 & 0,04 & 3,23 & 0,13 \\
5 & P5 & 4,46 & 0,04 & 2,43 & 0,10 \\
6 & P6 & 4,62 & 0,04 & 2,53 & 0,11 \\
7 & P7 & 4,55 & 0,04 & 2,31 & 0,10 \\
8 & P8 & 4,04 & 0,04 & 2,86 & 0,11 \\
9 & P9 & 4,93 & 0,05 & 3,23 & 0,15 \\
10 & P10 & 4,21 & 0,04 & 2,46 & 0,10 \\
11 & P11 & 2,83 & 0,03 & 3,02 & 0,08 \\
12 & P12 & 4,65 & 0,04 & 2,67 & 0,11 \\
13 & P13 & 4,58 & 0,04 & 3,08 & 0,13 \\
14 & P14 & 4,65 & 0,04 & 3,78 & 0,16 \\
15 & P15 & 4,61 & 0,04 & 3,88 & 0,16 \\
16 & P16 & 4,17 & 0,04 & 4,27 & 0,16 \\
17 & P17 & 4,68 & 0,04 & 4,27 & 0,18 \\
18 & P18 & 4,65 & 0,04 & 3,28 & 0,14 \\
19 & P19 & 4,45 & 0,04 & 3,62 & 0,15 \\
20 & P20 & 4,36 & 0,04 & 4,42 & 0,18 \\
21 & P21 & 4,36 & 0,04 & 4,47 & 0,18 \\
22 & P22 & 4,40 & 0,04 & 4,49 & 0,18 \\
23 & P23 & 4,61 & 0,04 & 3,08 & 0,13 \\
24 & P24 & 4,22 & 0,04 & 3,30 & 0,13 \\
25 & P25 & 2,87 & 0,03 & 3,39 & 0,09 \\
\hline & TOTAL & & & 0,66 \\
\hline & & 108,65 & & & \\
& & & & & \\
\hline Sin & & & \\
\hline
\end{tabular}

Sumber: Data primer diolah (2021) 
Berdasarkan hasil perhitungan CSI pada Tabel 6, diperoleh hasil dari atribut tingkat kinerja penyuluh menurut petani padi sawah di Kecamatan Pandawai adalah 0,66. Nilai tersebut berada pada interval 0,66 - 0,80 dengan kategori Puas. Nilai CSI tersebut menjelaskan bahwa secara umum petani padi sawah puas terhadap kinerja PPL di Kecamatan Pandawai. Hasil ini sejalan dengan penelitian Bella (Trisnaningtyas et al., 2020), yang menyatakan bahwa petani di Desa Senden Kecamatan Selo Kabupaten Boyolali puas terhadap kinerja penyuluh pertanian, dengan nilai CSI sebesar 0,74.

Kepuasan petani terhadap kinerja penyuluh pertanian terlihat pada keaktifan petani dalam menyampaikan permasalahan-permasalahan yang mereka hadapi dan kemampuan penyuluh dalam menerima dan memberikan solusi permasalahan. Akan tetapi penyuluh masih perlu melakukan perbaikan dan meningkatkan kinerja dalam upaya memaksimalkan kepuasaan petani sampai pada kategoti sangat puas.

Penyuluh pertanian perlu memperhatikan kesesuaian atribut-atribut pelayanan PPL pada analisis IPA dalam rangka pengadaan perbaikan dan peningkatan kinerja PPL. Nilai kesesuian atribut akan menunjukkan tingkatan prioritas atribut yang perlu diperbaiki dan ditingkatkan oleh penyuluh pertanian. Semakin kecil nilai kesesuaiannya menjadikan atribut pelayanan tersebut memiliki prioritas tinggi untuk diperbaiki dan ditingkatkan kinerjanya. Peningkatan pelaksanaan kinerja pada atribut tersebut akan meningkatkan nilai Weighted Score dan nilai CSI.

Hal lain yang perlu diperhatikan pada kepuasan petani adalah harapan petani. Faktor utama yang sangat mempengaruhi harapan petani adalah kebutuhan petani. Kebutuhan dasar petani menjadi faktor yang mempengaruhi besar harapan petani terhadap pelaksanaan kinerja penyuluh pertanian (Trisnaningtyas et al., 2020). Kepuasan petani terhadap kinerja PPL akan membentuk loyalitas petani pada setiap pelaksanaan kegiatan - kegiatan dalam penyuluhan pertanian. Penilaian kepuasan terhadap pelayanan akan mengarahkan pada loyalitas, semakin puas seseorang terhadap pelayanan maka akan semakin loyal (Sumarwan, 2008).

\section{KESIMPULAN DAN SARAN}

Kesesuain atribut pelayanan penyuluh berdasarkan perbandingan antara tingkat harapan terhadap tingkat kinerja penyuluh pertanian lapangan menurut petani padi sawah di Kecamatan 
Pandawai adalah 77,02\%. Dimana sebagian besar atribut pelayanan PPL di Kecamatan Pandawai belum mencapai kesesuaian atau masih terdapat kesenjangan.

Hasil analisis tingkat kepuasan petani padi sawah terhadap kinerja penyuluh pertanian lapangan di Kecamatan Pandawai adalah 0,66. Berada pada interval 0,66-0,80, dan masuk pada kategori Puas.

Dalam upaya peningkatan kualitas pelayanan penyuluh pertanian di Kecamatan Pandawai, sebaiknya sumber daya yang dimiliki dimanfaatkan dalam perbaikan dan peningkatan mutu pada atribut-atribut yang berada pada kuadran prioritas utama/kuadran A, dengan memperhatikan tingkat kesesuaian antara harapan dan kinerja penyuluh, sehingga bisa diurutkan prioritas setiap atribut. Pemanfaatan sumber daya pada peningkatan kualitas pelayanan di kuadaran C dan kuadran D akan menyebapkan pemborosan pada penggunaan sumber daya.

\section{DAFTAR PUSTAKA}

Ariana, S., Sundari, R. S., \& Umbara, D. S. (2021). Peran Penyuluh Pertanian Terhadap Hasil Produksi Padi Sawah Di Desa Cibuniasih Kecamatan Pancatengah Kabupaten Tasikmalaya. Mimbar Agribisnis: Jurnal Pemikiran Masyarakat
Ilmiah Berwawasan Agribisnis, 7(2), 1474. https://doi.org/10.25157/ma.v7i2.54 52

Arikunto, S. (2006). Prosuder Penelitian Suatu Pendekatan Praktik: Edisi Revisi VI. 2006. In Jakarta: Rineka Cipta.

Bahua, M. I. (2015). Penyuluhan dan Pemberdayaan Petani Indonesia. In Angewandte Chemie International Edition, 6(11), 951-952.

Bahua, M. I. (2016). Kinerja Penyuluh Pertanian. Gorontalo : Deepublish.

BPS Sumba Timur. (2019). Kabupaten Sumba Timur Dalam Angka 2019.

BPS Sumba Timur. (2020). Kecamatan Pandawai Dalam Angka 2020.

Hernanto, F. (1989). Ilmu Usahatani. Penebar Swadata.

Mahyuddin, T., Hanisah, H., \& Rahmi, C. L. (2018). Faktor-Faktor Yang Mempengaruhi Kinerja Penyuluh Pertanian Di Kabupaten Aceh Timur. Jurnal Penelitian Agrisamudra, 5(1), 22-29. https://doi.org/10.33059/jpas.v5i1.8 38

Makatita, J., \& Isbandi, S. D. (2014). Tingkat Efektivitas Penggunaan Metode Penyuluhan Pengembangan Ternak Sapi Potong di Kabupaten Buru Provinsi Maluku. AGROMEDIA: Berkala Ilmiah Ilmu-Ilmu Pertanian, 32(2), 64-74. https://doi.org/https://doi.org/10.47 728/ag.v32i2.95

Sumarwan, U. (2008). Perilaku Konsumen Teori dan Penerapannya dalam Pemasaran, Jakarta. 1-3.

Supranto, J. (2011). Pengukuran Tingkat Kepuasan Pelanggan untuk. Menaikkan Pangsa Pasar (Cetakan Keempat). Jakarta: PT. Rineka Cipta.

Syukri, S. H. A. (2014). Penerapan Customer Satisfaction Index (CSI) 
dan Analisis Gap pada Kualitas Pelayanan Trans Jogja. Jurnal Ilmiah Teknik Industri, 13(2). https://doi.org/https://doi.org/10.23 917/jiti.v13i2.618

Trisnaningtyas, B. P., Dalmiyatun, T., \& Gayatri, S. (2020). Tingkat Kepuasan Petani Terhadap Kinerja Penyuluh Pertanian Di Desa Senden Kecamatan Selo Kabupaten Boyolali. Agroland: Jurnal IlmuIlmu Pertanian, 27(2), 191-203. https://doi.org/10.22487/agrolandna sional.v27i2.463
Undang-Undang Republik Indonesia No.13 Tahun 2003 Tentang Ketenagakerjaan, Undang-undang No.13 Tahun 2003 (2003).

Undang-Undang Republik Indonesia Nomor 16 Tahun 2006 Tentang Sistem Penyuluhan Pertanian, Perikanan dan Kehutanan, Undang Undang Republik Indonesia Nomor 16 Tahun 20061 (2006).

Wijaya, T. (2018). Manajemen Kualitas Jasa (Desain Servqual,QFD dan Kano). In Indeks: Vol. Edisi 2. 